\title{
Capsule Commentary on Linzer et al., Work Condition Interventions Affect Quality and Errors in Primary Care? Results from the Healthy Work Place Study
}

\author{
Rachel Hess, MD, MS \\ City, UT, USA. \\ $\mathrm{J}$ Gen Intern Med 32(1):89 \\ DOI: $10.1007 / \mathrm{s} 11606-016-3914-9$ \\ (c) Society of General Internal Medicine 2016
}

Division of Health System Innovation and Research, Department of Population Health Sciences, University of Utah School of Medicine, Salt Lake

I $\mathrm{n}$ a randomized quality improvement study, Linzer and colleagues $^{1}$ provided practices with feedback regarding the effect of work-life and work conditions on error reduction and quality outcomes. Among 34 primary care practices in the Upper Midwest and New York City, 17 received summaries of an Office and Work Life (OWL) measure to develop practicespecific quality improvement projects, which included improving communication among providers, workflow redesign, and chronic disease management programs. In the primary analyses, there was no difference in error reduction or in quality outcomes between the intervention and control practices.

The authors' findings support a previous MEMO [Minimizing Error, Maximizing Outcome $]^{2}$ model which linked work control to reduced provider stress, improved satisfaction, and reduction in errors. Interestingly, in the current study, targeting communication and workflow paradoxically reduced provider sense of work control, which may have limited any positive intervention impact in other areas. This is not unexpected, as the quality improvement teams "consisted of clinic managers and/or leaders, members of the department, and relevant providers and clinic staff." ${ }^{1}$ Providers not involved in the quality improvement team may have felt that the quality improvement initiatives reduced their autonomy and work control. It will be important in future work to examine the impact of quality improvement programs not only on patient outcomes, but also on practice providers and staff. In addition, future work should examine the impact of quality improvement team composition and implementation strategy on the clinical and practice-centered outcomes put forth in this work, and employ similar structural equation modeling to account for the interplay.

This study, in conjunction with other randomized trials using quality improvement techniques, ${ }^{3}$ challenges the notion that quality improvement studies cannot be rigorous. This is important as we move beyond translation from bench to bedside, towards bedside to practice and populations. It facilitates research in partnership with academic and community practices ${ }^{4}$ and supports the national call for a more pragmatic research infrastructure. It also cautions that work seen as quality improvement can have unintended downstream consequences that must be rigorously evaluated in order to better understand how to achieve benefit for all involved.

Corresponding Author: Rachel Hess, MD, MS; Division of Health System Innovation and Research, Department of Population Health Sciences, University of Utah School of Medicine, Salt Lake City, UT, USA (e-mail: Rachel.Hess@hsc.utah.edu).

\section{Compliance with Ethical Standards:}

Conflict of Interest: The author has no conflicts of interest with this article.

\section{REFERENCES}

1. Linzer M, Poplau S, Brown R, et al. Do work condition interventions affect quality and errors in primary care? Results from the Healthy Work Place study. J Gen Intern Med. 2016. doi:10.1007/s11606-016-3856-2.

2. Linzer $\mathbf{M}$, et al. Working conditions in primary care: physician reactions and care quality. Ann Intern Med. 2009;151(1):28-36. W6-9.

3. Marsteller JA, et al. A multicenter, phased, cluster-randomized controlled trial to reduce central line-associated bloodstream infections in intensive care units. Crit Care Med. 2012;40(11):2933-2939.

4. Mann DM, Hess R. Academic medical center R\&D: a call for creating an operational research infrastructure within the academic medical center. Clin Transl Sci. 2015;8(6):871-872. 